\title{
Evaluation of the transporter-mediated herb-drug interaction potential of DA-9801, a standardized dioscorea extract for diabetic neuropathy, in human in vitro and rat in vivo
}

Im-Sook Song ${ }^{1}$, Tae Yeon Kong ${ }^{2}$, Hyeon-Uk Jeong ${ }^{2}$, Eun Nam Kim², Soon-Sang Kwon², Hee Eun Kang ${ }^{2}$, Sang-Zin $\mathrm{Choi}^{3}$, Miwon Son ${ }^{3}$ and Hye Suk Lee ${ }^{2^{*}}$

\begin{abstract}
Background: Drug transporters play important roles in the absorption, distribution, and elimination of drugs and thereby, modulate drug efficacy and toxicity. With a growing use of poly pharmacy, concurrent administration of herbal extracts that modulate transporter activities with drugs can cause serious adverse reactions. Therefore, prediction and evaluation of drug-drug interaction potential is important in the clinic and in the drug development process. DA-9801, comprising a mixed extract of Dioscoreae rhizoma and Dioscorea nipponica Makino, is a new standardized extract currently being evaluated for diabetic peripheral neuropathy in a phase II clinical study.

Method: The inhibitory effects of DA-9801 on the transport functions of organic cation transporter (OCT)1, OCT2, organic anion transporter (OAT)1, OAT3, organic anion transporting polypeptide (OATP)1B1, OATP1B3, P-glycoprotein (P-gp), and breast cancer resistance protein (BCRP) were investigated in HEK293 or LLC-PK1 cells. The effects of DA-9801 on the pharmacokinetics of relevant substrate drugs of these transporters were also examined in vivo in rats. Results: DA-9801 inhibited the in vitro transport activities of OCT1, OCT2, OAT3, and OATP1B1, with IC 50 values of 106, $174,48.1$, and $273 \mu \mathrm{g} / \mathrm{mL}$, respectively, while the other transporters were not inhibited by $300 \mu \mathrm{g} / \mathrm{mL}$ DA-9801. To investigate whether this inhibitory effect of DA-9801 on OCT1, OCT2, and OAT3 could change the pharmacokinetics of their substrates in vivo, we measured the pharmacokinetics of cimetidine, a substrate for OCT1, OCT2, and OAT3, and of furosemide, a substrate for OAT1 and OAT3, by co-administration of DA-9801 at a single oral dose of 1,000 mg/kg. Pre-dose of DA-9801 5 min or $2 \mathrm{~h}$ prior to cimetidine administration decreased the $C_{\max }$ of cimetidine in rats. However, DA-9801 did not affect the elimination parameters such as half-life, clearance, or amount excreted in the urine, suggesting that it did not inhibit elimination process of cimetidine, which is governed by OCT1, OCT2, and OAT3. Moreover, DA-9801 did not affect the pharmacokinetic characteristics of furosemide, as evidenced by its unchanged pharmacokinetic parameters.
\end{abstract}

Conclusion: Inhibitory effects of DA-9801 on OCT1, OCT2, and OAT3 observed in vitro may not necessarily translate into in vivo herb-drug interactions in rats even at its maximum effective dose.

Keywords: Transporter-mediated herb-drug interaction, DA-9801, OCT1, OCT2, OAT3, Cimetidine, Furosemide

\footnotetext{
* Correspondence: sianalee@catholic.ac.kr

${ }^{2}$ College of Pharmacy, The Catholic University of Korea, Bucheon 420-743,

Korea

Full list of author information is available at the end of the article
} 


\section{Background}

Diabetic peripheral neuropathy is one of the most debilitating complications of type 1 and type 2 diabetes and its histopathology is characterized by axonal degeneration, demyelination, and atrophy [1,2]. Approximately $50 \%$ of diabetes patients have symptoms of diabetic peripheral neuropathy [3]. The pursuit of new drugs for the treatment of diabetic peripheral neuropathy has led to the identification of DA-9801, an ethanol extract of Dioscoreae rhizoma and Dioscorea nipponica Makino, as a potential therapeutic agent; it is currently being evaluated in a phase II diabetic neuropathy clinical study in Korea [4]. DA-9801 may improve diabetic neuropathy-induced tissue damage by increasing nerve growth factor levels in target tissues, improving nerve conduction velocity, and promoting recovery from neuronal degeneration $[4,5]$. It also showed neuroprotective effects on peripheral nerves in streptozotocin-induced diabetic rats [6,7].

Herb-drug interactions, resulting from concurrent use of herbal drugs may cause adverse reactions such as toxicity and treatment failure [8]. The mechanisms underlying herb-drug interactions involve inhibition or induction of cytochrome P450 (CYP) enzymes, UDP-glucuronosyltransferase (UGT) enzymes, and drug transporters $[9,10]$. St. John's wort (Hypericum perforatum), ginkgo (Ginko biloba), ginseng (Panax ginseng), milk thistle (Silybum marianum), and licorice (Glycyrrhiza glabra) have been reported to cause drug interactions with anticoagulants, antiretroviral drugs, anticancer drugs, immunosuppressants, or antidepressants [11-15]. Therefore, it is necessary to evaluate herb-drug interactions in order to prevent potentially dangerous clinical outcomes. DA-9801 did not potently inhibit CYP 1A2, 2A6, 2B6, 2C8, 2C9, 2C19, 2D6, or 3A4 and UGT 1A1, 1A4, 1A9, or 2B7 in human liver microsomes, indicating that DA-9801 may not inhibit the metabolism of CYP- and UGT-catalyzed drugs in humans [8].

In this study, we investigated possible herb-drug interactions involving drug transporters by using HEK293 and LLC-PK1 cell systems overexpressing clinically important uptake and efflux transporters such as organic cation transporter (OCT) 1, OCT2, organic anion transporter (OAT) 1, OAT3, organic anion transporting polypeptide (OATP) 1B1, OATP1B3, P-glycoprotein (P-gp or MDR1), and breast cancer resistance protein (BCRP) [16]. We also investigated the effects of DA-9801 on the pharmacokinetics of substrates for the effected transporters in vivo in rats.

\section{Methods}

\section{Chemicals and reagents}

Dried Dioscoreae rhizoma and rhizome of Dioscorea nipponica Makino were purchased at a speciality market for traditional herbal medicine (Dong Kyung Pharm. Co.,
Seoul, Korea) and their identity was kindly confirmed by Prof. Yeong Bae Seo (a specialist in plant classification, Natural Products Research Institute, Seoul National University, Seoul, Korea). The voucher specimens for Dioscoreae rhizoma (deposit code, KNJS) and rhizome of Dioscorea nipponica Makino (deposit code, LY026) were deposited at Dong-A ST Research Center (Youngin, Korea).

DA-9801 was prepared as previously reported [5]. Briefly, dried Dioscoreae rhizoma and rhizome of Dioscorea nipponica Makino were mixed in a specific ratio (3.5:1) and extracted with 50\% ethanol three times at room temperature for $48 \mathrm{~h}$. After filtration, the aqueous ethanol extract was evaporated under reduced pressure and lyophilized to completely remove the residual solvent and to yield brown powder. The levels of two marker components - dioscin (1.37\%) and allantoin (3.29\%) - in DA-9801 were determined using high performance liquid chromatography [5].

$\left[{ }^{3} \mathrm{H}\right]$ Methyl-4-phenylpyridinium $\left(\mathrm{MPP}^{+}, 2.9 \mathrm{TBq} / \mathrm{mmol}\right)$, $\left[{ }^{3} \mathrm{H}\right]$ para-aminohippuric acid (PAH, $\left.0.13 \mathrm{TBq} / \mathrm{mmol}\right),\left[{ }^{3} \mathrm{H}\right]$ estrone-3-sulfate (ES, $2.12 \mathrm{TBq} / \mathrm{mmol}),\left[{ }^{3} \mathrm{H}\right]$ digoxin $(1.103$ $\mathrm{TBq} / \mathrm{mmol}$ ) and $\left[{ }^{3} \mathrm{H}\right]$ estradiol-17 $\beta$-D-glucuronide (EG, $2.22 \mathrm{TBq} / \mathrm{mmol}$ ) were purchased from Perkin Elmer Inc. (Boston, MA, USA). Cimetidine, furosemide and tiapride were obtained from Sigma-Aldrich Co. (St. Louis, MO, USA). 4-Hydroxydiclofenac- $d_{4}$ was obtained from Toronto Research Chemicals Inc. (North York, Ontario, Canada). All other chemicals were reagent grade and all solvents were HPLC grade.

\section{Inhibitory effects of DA-9801 on transport activities}

HEK293 cells transiently overexpressing OAT1, OAT3, OCT1, OCT2, OATP1B1, and OATP1B3 transporters were purchased from Corning-Gentest (Tewksbury, MA, USA). The cells were maintained at $37^{\circ} \mathrm{C}$ in a humidified atmosphere of $8 \% \mathrm{CO}_{2}$, in Dulbecco's modified Eagle's medium supplemented with $10 \%$ fetal bovine serum, $5 \mathrm{mM}$ non-essential amino acids, and $100 \mathrm{U} / \mathrm{mL}$ penicillinstreptomycin. For experiments, $10^{5}$ cells were seeded in 96-well plates. After $24 \mathrm{~h}$, the growth media were discarded and the attached cells were washed with Hank's balanced salt solution (HBSS) and preincubated for $20 \mathrm{~min}$ in $\mathrm{HBSS}$ at $37^{\circ} \mathrm{C}$. To examine the effects of DA-9801 on transporter activity, the uptake of $0.1 \mu \mathrm{M}$ $\left[{ }^{3} \mathrm{H}\right] \mathrm{MPP}^{+}$for OCT1 and OCT2, $1 \mu \mathrm{M}\left[{ }^{3} \mathrm{H}\right] \mathrm{PAH}$ for OAT1, $0.1 \mu \mathrm{M}\left[{ }^{3} \mathrm{H}\right] \mathrm{ES}$ for OAT3 and OATP1B1, and $0.1 \mu \mathrm{M}\left[{ }^{3} \mathrm{H}\right] \mathrm{EG}$ for OATP1B3 was measured in the presence of DA-9801 $(1-300 \mu \mathrm{g} / \mathrm{mL})$ for $10 \mathrm{~min}$ at $37^{\circ} \mathrm{C}$. The cells were then washed three times with $100 \mu \mathrm{L}$ of ice-cold HBSS immediately after placing the plates on ice and lysed with $10 \%$ SDS. The radioactivity of the probe substrate in the cells was measured using a liquid scintillation counter. 
LLC-PK1-MDR1 (LLC-PK1 cells stably expressing P-gp; purchased from Corning-Gentest) and LLC-PK1-BCRP (LLC-PK1 cells stably expressing BCRP; obtained from Dr. A.H. Schinkel, Netherlands Cancer Institute, Amsterdam, The Netherlands) cells were used for the comparison of the basal to apical (B to A) transport rate of $\left[{ }^{3} \mathrm{H}\right]$ digoxin and $\left[{ }^{3} \mathrm{H}\right] \mathrm{ES}$ in the absence and presence of DA-9801. Briefly, the cells were seeded on filter inserts for 24-transwell plates at a density of $5 \times 10^{5}$ cells and grown for 5 days. The integrity of the cell monolayers was evaluated prior to transport experiments by measuring transepithelial electrical resistance (TEER) and TEER values in the range of $300-850 \Omega \cdot \mathrm{cm}^{2}$ were used in the transport experiment [17]. For measurement of B to A transport, $0.8 \mathrm{~mL}$ of HBSS containing $\left[{ }^{3} \mathrm{H}\right]$ digoxin or $\left[{ }^{3} \mathrm{H}\right] \mathrm{ES}(0.1 \mu \mathrm{M}$ each $)$ and DA-9801 $(1-300 \mu \mathrm{g} / \mathrm{mL})$ was added on the basal side, and $0.3 \mathrm{~mL}$ of fresh HBSS was added on the apical side. At every $15 \mathrm{~min}, 0.2 \mathrm{~mL}$ of HBSS sample in the apical side was removed and replaced with $0.2 \mathrm{~mL}$ of fresh HBSS for $1 \mathrm{~h}$.

\section{Effect of DA-9801 pretreatment on the pharmacokinetics of cimetidine and furosemide in rats}

Sprague-Dawley (SD) rats (male, 7 weeks old) were obtained from Samtako Co. (Osan, Korea). Animals were acclimated for 1 week in a temperature controlled room $\left(23 \pm 2^{\circ} \mathrm{C}\right)$, with a relative humidity of $55 \pm 10 \%$, an illumination intensity of 150-300 lux, a frequency of air ventilation of $15-20$ times/h, and a $12 \mathrm{~h}$ illumination (07:00-19:00). Food and water were supplied ad libitum. All animal procedures were approved by the Animal Care and Use Committee in The Catholic University of Korea.

Rats were cannulated with polyethylene tubing (PE-50, Natsume Co, Tokyo, Japan) in the jugular vein for sampling under anesthesia with isoflurane. Each rat was housed individually in a rat metabolic cage and allowed to recover from anesthesia. The rats were not restrained at any time during the study. Heparinized isotonic saline $(10 \mathrm{U} / \mathrm{mL})$ was used to flush the catheters to prevent blood clotting. The rats were fasted for more than $12 \mathrm{~h}$ before oral administration of drugs.

DA-9801 was dissolved in DMSO/propylene glycol/ deionized water $(2: 6: 2, \mathrm{v} / \mathrm{v})$, and a $1,000 \mathrm{mg} / \mathrm{kg}$ dose was administered to the rats by oral gavages (vehicle dosing volume, $3 \mathrm{~mL} / \mathrm{kg}$ ) at $5 \mathrm{~min}$ and $2 \mathrm{~h}$ prior to the oral administration of cimetidine at a dose of $10 \mathrm{mg} / \mathrm{kg}$ [18] and furosemide at a dose of $10 \mathrm{mg} / \mathrm{kg}$ [19] (vehicle dosing volume, $2 \mathrm{~mL} / \mathrm{kg}$ ). Cimetidine and furosemide were dissolved in deionized water and DMSO/propylene glycol/deionized water $(2: 4: 4, \mathrm{v} / \mathrm{v} / \mathrm{v})$, respectively. Blood samples were collected prior to cimetidine and furosemide administration (to serve as a control), 5, 15, 30, $45 \mathrm{~min}$, and $1,1.5,2,3,4,6,8 \mathrm{~h}$ after oral administration of cimetidine and furosemide. After centrifugation of blood samples at 13,000 rpm for $5 \mathrm{~min}$, plasma samples $(30 \mu \mathrm{L})$ were collected and stored at $-80^{\circ} \mathrm{C}$ until analysis. At $24 \mathrm{~h}$ after drug administration, the metabolic cage was rinsed with distilled water $(10 \mathrm{~mL})$, and the rinsed solutions were combined with the pooled urine samples collected for $24 \mathrm{~h}$. After measuring the exact volume of the urine samples, $30 \mu \mathrm{L}$ aliquots of each sample were stored at $-20^{\circ} \mathrm{C}$ until analysis.

\section{LC-MS/MS analysis of cimetidine}

The concentrations of cimetidine were analyzed using a modified liquid chromatography tandem mass spectrometry (LC-MS/MS) method reported by Sun et al. [20]. Thirty $\mu \mathrm{L}$ of rat plasma samples, calibration standards, and quality control (QC) samples were vortex-mixed with $100 \mu \mathrm{L}$ of tiapride in methanol $(5 \mathrm{ng} / \mathrm{mL}$, internal standard, IS) for $3 \mathrm{~min}$ at a high speed. After centrifugation at $13,000 \mathrm{rpm}$ at $4^{\circ} \mathrm{C}$ for $8 \mathrm{~min}, 50 \mu \mathrm{L}$ of the supernatant was diluted with $50 \mu \mathrm{L}$ of water. An aliquot $(3 \mu \mathrm{L})$ was injected into the LC-MS/MS system. Ten $\mu \mathrm{L}$ of rat urine samples, urine calibration standards, and QC samples were vortexmixed with $1,000 \mu \mathrm{L}$ of tiapride in methanol $(5 \mu \mathrm{g} / \mathrm{mL})$ for $3 \mathrm{~min}$ at high speed. After centrifugation at 13,000 rpm at $4^{\circ} \mathrm{C}$ for $8 \mathrm{~min}, 10 \mu \mathrm{L}$ of the supernatant was diluted with $200 \mu \mathrm{L}$ of $30 \%$ methanol and an aliquot $(3 \mu \mathrm{L})$ was injected into the LC-MS/MS system. Plasma calibration standards were $1-1000 \mathrm{ng} / \mathrm{mL}$ and urine calibration standards were $1-200 \mu \mathrm{g} / \mathrm{mL}$.

The LC-MS/MS system consisted of an Agilent 1200 series (Agilent Technologies, Wilmington, DE, USA) and a 6460 triple quadrupole mass spectrometer (Agilent Technologies). Mass Hunter software (Agilent Technologies) was used for LC-MS/MS system control and data processing. Separation was performed on a Luna phenyl-hexyl column $(5 \mu \mathrm{m}, 2.1 \mathrm{~mm}$ i.d. $\times 100 \mathrm{~mm}$, Phenomenex, Torrance, CA, USA) with a gradient elution of $5 \%$ methanol with $10 \mathrm{mM}$ ammonium formate (mobile phase A) and 95\% methanol with $10 \mathrm{mM}$ ammonium formate (mobile phase B) at a flow rate of $0.4 \mathrm{~mL} / \mathrm{min}$ : $30 \%$ mobile phase B for $0.5 \mathrm{~min}, 30 \%$ to $85 \%$ mobile phase B for $0.5 \mathrm{~min}, 85 \%$ mobile phase $\mathrm{B}$ for $3.0 \mathrm{~min}, 85 \%$ to $30 \%$ mobile phase B for $0.1 \mathrm{~min}$, $30 \%$ mobile phase $\mathrm{B}$ for $4 \mathrm{~min}$. The column and autosampler were maintained at $50^{\circ} \mathrm{C}$ and $5^{\circ} \mathrm{C}$, respectively. Electrospray ionization (ESI) source settings for ionization of cimetidine in the positive mode were as follows: gas temperature, $350^{\circ} \mathrm{C}$; gas flow, $10 \mathrm{~L} / \mathrm{min}$; nebulizer, $35 \mathrm{psi}$; sheath gas temperature, $330^{\circ} \mathrm{C}$; sheath gas flow, $11 \mathrm{~L} / \mathrm{min}$, and capillary voltage, $3500 \mathrm{~V}$. Fragmentation of molecular ions for cimetidine and tiapride was performed at a collision energy of $10 \mathrm{eV}$ and $18 \mathrm{eV}$, respectively. Selected reaction monitoring (SRM) mode was used for quantification: $m / z 253.1 \rightarrow 159.1$ for cimetidine and $m / z$ $329.1 \rightarrow 256$ for tiapride. 

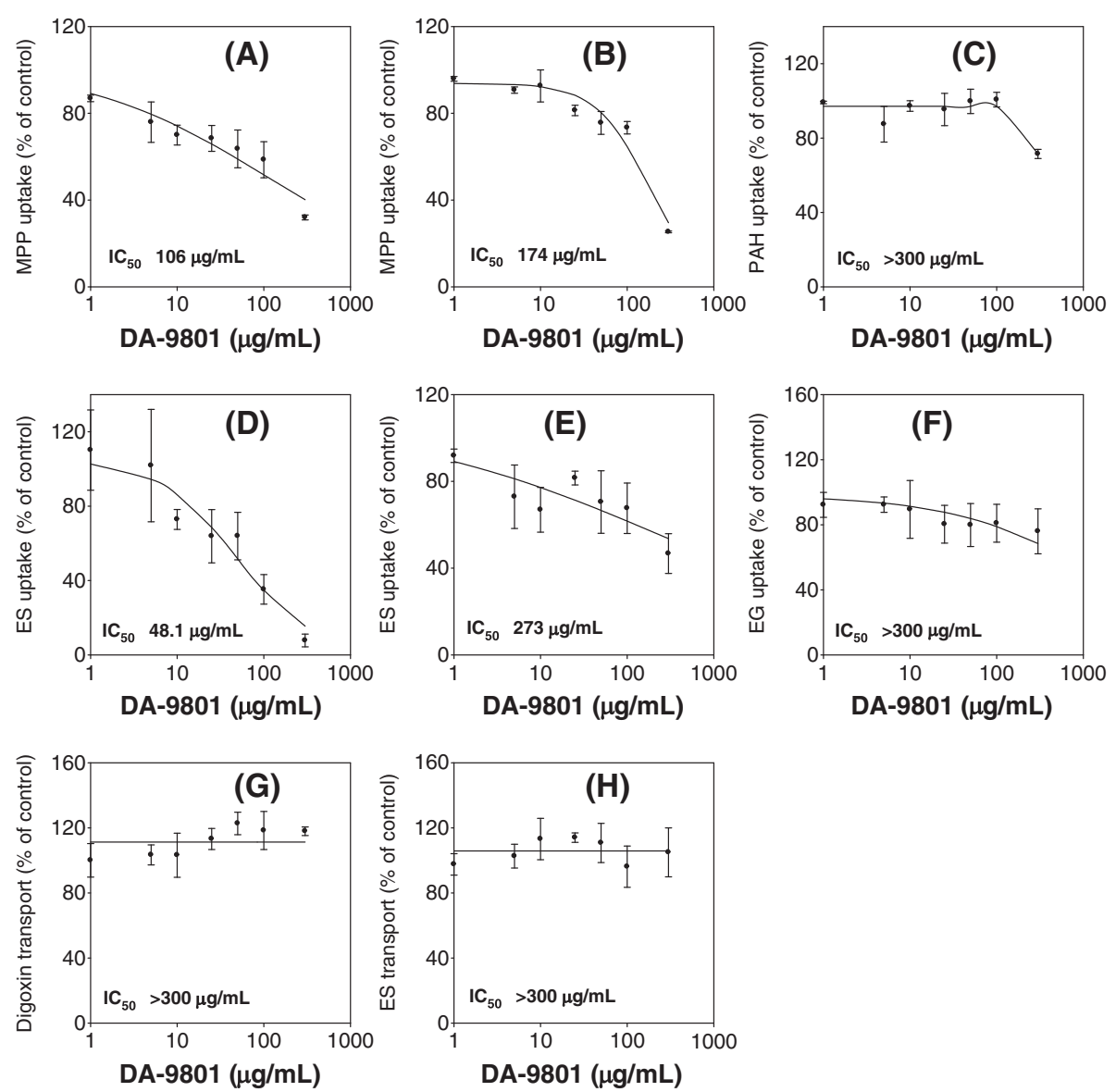

Figure 1 Inhibitory effect of DA-9801 on the transport activities of OCT1 (A), OCT2 (B), OAT1 (C), OAT3 (D), OATP1B1 (E), OATP1B3 (F), P-gp (G), and BCRP (H). Inhibitory effect of DA-9801 $(1-300 \mu \mathrm{g} / \mathrm{ml})$ on the uptake of $0.1 \mu \mathrm{M}\left[^{3} \mathrm{H}\right]$ methyl-4-phenylpyridinium (MPP ; a substrate for OCT1 and OCT2), $1 \mu \mathrm{M}\left[{ }^{14} \mathrm{C}\right]$ para-aminohippuric acid (PAH; a substrate for OAT1), $0.1 \mu \mathrm{M}\left[{ }^{3} \mathrm{H}\right]$ estrone-3-sulfate (ES; a substrate for OAT3, OATP1B1, and BCRP), $0.1 \mu \mathrm{M}\left[{ }^{3} \mathrm{H}\right.$ ]estradiol-173-D-glucuronide (EG; a substrate for OATP1B3), and $0.1 \mu \mathrm{M}\left[^{3} \mathrm{H}\right]$ digoxin (a substrate for P-gp) were measured. Data point represents the mean $\pm S D$ of three independent experiments. Data were fitted to an inhibitory effect $E_{\max }$ model and the $I C_{50}$ value was calculated.

\section{LC-MS/MS analysis of furosemide}

The concentrations of furosemide were analyzed using a modified LC-MS/MS method reported by Sora et al. [21]. Thirty $\mu \mathrm{L}$ of rat plasma samples, calibration standards, and QC samples were vortex-mixed with $100 \mu \mathrm{L}$ of 4-hydroxydiclofenac- $d_{4}$ in methanol (500 ng/mL, IS) for $3 \mathrm{~min}$ at a high speed. After centrifugation at $13,000 \mathrm{rpm}$ at $4^{\circ} \mathrm{C}$ for $8 \mathrm{~min}, 60 \mu \mathrm{L}$ of the supernatant was diluted with $40 \mu \mathrm{L}$ of water. An aliquot $(5 \mu \mathrm{L})$ was injected into the LC-MS/MS. Ten $\mu \mathrm{L}$ of rat urine samples,

Table 1 Pharmacokinetic parameters of cimetidine (10 mg/kg) after co-administration of DA-9801 at a single oral dose of $1,000 \mathrm{mg} / \mathrm{kg}$

\begin{tabular}{|c|c|c|c|c|}
\hline & \multicolumn{2}{|c|}{5 min pre-dose of DA-9801 $(n=5)$} & \multicolumn{2}{|c|}{2 h pre-dose of DA-9801 $(n=5)$} \\
\hline & Control & DA-9801 & Control & DA-9801 \\
\hline $\mathrm{T}_{\max }(\mathrm{h})$ & $0.700 \pm 0.326$ & $2.50 \pm 0.707^{* *}$ & $0.300 \pm 0.112$ & $1.20 \pm 1.24$ \\
\hline$C_{\max }(n g / m L)$ & $652 \pm 120$ & $337 \pm 100^{* *}$ & $995 \pm 305$ & $532 \pm 175^{*}$ \\
\hline$t_{1 / 2}(h)$ & $1.12 \pm 0.130$ & $1.45 \pm 0.620$ & $1.09 \pm 0.139$ & $1.20 \pm 0.125$ \\
\hline$A \cup C_{8 h}(\mu \mathrm{g} / \mathrm{mL} \cdot h)$ & $1.77 \pm 0.314$ & $1.34 \pm 0.154$ & $1.80 \pm 0.372$ & $1.78 \pm 0.290$ \\
\hline$A \cup C_{\infty}(\mu \mathrm{g} / \mathrm{mL} \cdot \mathrm{h})$ & $1.79 \pm 0.313$ & $1.41 \pm 0.122$ & $1.82 \pm 0.382$ & $1.82 \pm 0.304$ \\
\hline $\mathrm{CL} / \mathrm{F}(\mathrm{mL} / \mathrm{min} / \mathrm{kg})$ & $95.2 \pm 15.7$ & $119 \pm 9.56$ & $94.1 \pm 15.5$ & $93.5 \pm 13.8$ \\
\hline Amount excreted in urine (\% of dose) & $23.2 \pm 4.53$ & $16.3 \pm 10.9$ & $24.1 \pm 11.2$ & $27.4 \pm 3.23$ \\
\hline
\end{tabular}




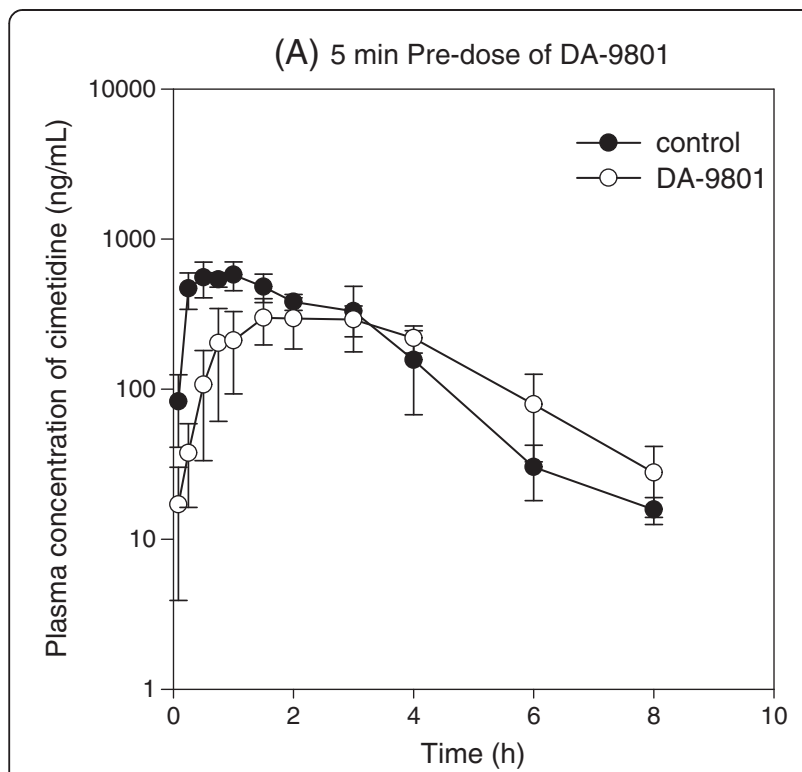

(B) $2 \mathrm{~h}$ Pre-dose of DA-9801

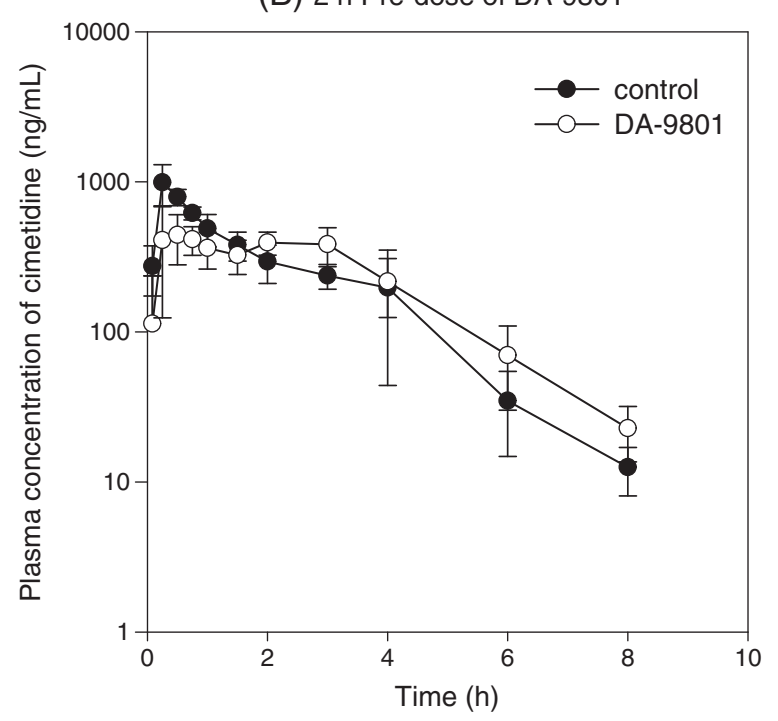

Figure 2 Plasma concentration-time curves of cimetidine. (A) Plasma concentration profile of cimetidine in rats after oral administration of $10 \mathrm{mg} / \mathrm{kg}$ cimetidine alone $(\bullet)$ and cimetidine with 5 min pre-dose of 1,000 mg/kg DA-9801 (०). (B) Plasma concentration profile of cimetidine in rats after oral administration of $10 \mathrm{mg} / \mathrm{kg}$ cimetidine alone $(\bullet)$ and cimetidine with $2 \mathrm{~h}$ pre-dose of $1,000 \mathrm{mg} / \mathrm{kg}$ DA-9801 (०). Each data point represents the mean \pm S.D. of five rats.

calibration standards, and QC samples were vortex-mixed with $1000 \mu \mathrm{L}$ of 4-hydroxydiclofenac- $d_{4}$ in methanol $(15 \mu \mathrm{g} / \mathrm{mL})$ for $3 \mathrm{~min}$ at high speed. After centrifugation at $13,000 \mathrm{rpm}$ at $4^{\circ} \mathrm{C}$ for $8 \mathrm{~min}$, the aliquot $(5 \mu \mathrm{L})$ was injected into the LC-MS/MS. Plasma calibration standards were $0.02-20 \mu \mathrm{g} / \mathrm{mL}$ and urine calibration standards were $1-200 \mu \mathrm{g} / \mathrm{mL}$. Separation was performed on a Pinnacle DB Biphenyl column $(3 \mu \mathrm{m}, 2.1 \mathrm{~mm}$ i.d. $\times 50 \mathrm{~mm}$, RESTEK, USA) using gradient elution of $5 \%$ methanol in
$0.1 \%$ formic acid (mobile phase A) and $95 \%$ methanol in $0.1 \%$ formic acid (mobile phase B) at a flow rate of $0.3 \mathrm{~mL} / \mathrm{min}$ : $50 \%$ mobile phase B for $0.4 \mathrm{~min}, 50 \%$ to $95 \%$ mobile phase B for $0.1 \mathrm{~min}$, 95\% mobile phase B for $4.0 \mathrm{~min}, 95 \%$ to $50 \%$ mobile phase B for $0.1 \mathrm{~min}, 50 \%$ mobile phase $\mathrm{B}$ for $4.0 \mathrm{~min}$. The column and autosampler were maintained at $50^{\circ} \mathrm{C}$ and $5^{\circ} \mathrm{C}$, respectively. ESI source settings for ionization of furosemide and IS in the negative mode were as follows: gas temperature, $350^{\circ} \mathrm{C}$; gas flow, $10 \mathrm{~L} / \mathrm{min}$; nebulizer, $35 \mathrm{psi}$; sheath gas temperature, $350^{\circ} \mathrm{C}$; sheath gas flow, $11 \mathrm{~L} / \mathrm{min}$, and capillary voltage, $3500 \mathrm{~V}$. Fragmentation of molecular ions for furosemide and 4-hydroxydiclofenac- $d_{4}$ was performed at a collision energy of $7 \mathrm{eV}$ and $4 \mathrm{eV}$, respectively. SRM mode was used for quantification: $\mathrm{m} / \mathrm{z} 329.1 \rightarrow 284.9$ for furosemide and $m / z 315.1 \rightarrow 270.9$ for 4-hydroxydiclofenac- $d_{4}$.

\section{Pharmacokinetic and statistical analyses}

In the inhibition studies, the percentages of inhibition were calculated using the ratio of the transport rate of probe substrates with or without DA-9801 and the relevant data were fitted to an inhibitory effect model [i.e. $v=E_{\max }\left(1-\frac{[I]}{I C_{50}+[I]}\right)$ ] [22]. Calculations were performed using WinNonlin software (ver. 2.0, Pharsight, Mountain View, LA).

In the in vivo rat studies, non-compartmental pharmacokinetic analysis was also performed using the WinNonlin software. The area under the plasma concentration-time curve (AUC) was calculated using the linear trapezoidal method. The area from the last datum point to time infinity $\left(\mathrm{AUC}_{\infty}\right)$ was estimated by dividing the last measured concentration in plasma by the terminal rate constant. The terminal elimination half-life $\left(t_{1 / 2}\right)$ and the systemic clearance $(\mathrm{CL} / \mathrm{F})$ were determined.

Statistical significance was analyzed using the MannWhitney $\mathrm{U}$ test, and values of $p<0.05$ were considered statistically significant. The SPSS software package (ver. 19.0, SPSS, Chicago, IL) was used for statistical analysis.

\section{Results}

Inhibitory effect of DA-9801 on the activities of drug transporters

To characterize the inhibitory effect of DA-9801 on the uptake transporters, we measured the uptake of representative substrates for each transporter in HEK293 cells overexpressing OAT1, OAT3, OCT1, OCT2, OATP1B1, and OATP1B3 in the presence of DA-9801 $(1-300 \mu \mathrm{g} / \mathrm{mL})$. DA-9801 inhibited the transport activity of OCT1, OCT2, OAT3, and OATP1B1 with $\mathrm{IC}_{50}$ values of $106,174,48.1$, and $273 \mu \mathrm{g} / \mathrm{mL}$, respectively (Figure $1 \mathrm{~A}, \mathrm{~B}, \mathrm{D}$, and $\mathrm{E}$ ). However, DA-9801 did not inhibit $50 \%$ of the transport activity of OAT1 and OATP1B3 at its highest 
concentration used in this study $(300 \mu \mathrm{g} / \mathrm{mL})$. Therefore, we could not calculate $\mathrm{IC}_{50}$ values for these transporters (Figure $1 \mathrm{C}$ and $\mathrm{F}$ ). We further examined the inhibitory effect of DA-9801 on P-gp (MDR1) and BCRP function, by examining its effect on the $\mathrm{B}$ to $\mathrm{A}$ transport rate of digoxin and ES in LLC-PK1-MDR1 cells and LLC-PK1-BCRP cells, respectively. Efflux of digoxin and ES via P-gp and BCRP, respectively, was not inhibited by the presence of DA-9801 at concentrations up to $300 \mu \mathrm{g} / \mathrm{mL}$ (Figure $1 \mathrm{G}$ and $\mathrm{H}$ ).

\section{Effects of DA-9801 on the pharmacokinetics of cimetidine} and furosemide in rats

To assess the relevance of the DA-9801 $\mathrm{IC}_{50}$ values obtained in vitro to the in vivo DA-9801 herb-drug interaction with substrates for OCT1, OCT2, and/or OAT3, cimetidine was selected as a substrate for OCT1, OCT2 and OAT3 [23] and furosemide for OAT3 [24]. DA-9801 was orally administered $5 \mathrm{~min}$ and $2 \mathrm{~h}$ prior to the administration of cimetidine or furosemide.

The $\mathrm{AUC}_{8 \mathrm{~h}}, \mathrm{AUC}_{\infty}, \mathrm{CL} / \mathrm{F}$, and $\mathrm{t}_{1 / 2}$ of cimetidine were not changed by pre-dose of DA-9801, either at $5 \mathrm{~min}$ or $2 \mathrm{~h}$. Consequently, the amount of cimetidine excreted in urine was not changed by the pretreatment of DA-9801. In contrast, 5 min pre-dose of DA-9801 delayed $\mathrm{T}_{\max }$ and decreased $\mathrm{C}_{\max }$ of cimetidine. $2 \mathrm{~h}$ pre-dose of DA-9801 decreased $C_{\max }$ without affecting $T_{\max }$ of cimetidine (Table 1 and Figure 2).

In contrast to these cimetidine-related observation, the pharmacokinetic parameters such as $\mathrm{T}_{\max }, \mathrm{C}_{\max }, \mathrm{AUC}_{8 \mathrm{~h}}$, $\mathrm{AUC}_{\infty}, \mathrm{CL} / \mathrm{F}, \mathrm{t}_{1 / 2}$, and the amount of furosemide excreted in urine were not affected by the co-administration of DA-9801 either $5 \mathrm{~min}$ or $2 \mathrm{~h}$ prior to furosemide (Table 2 and Figure 3).

\section{Discussion}

The recent trend toward the use of poly pharmacy, which comprises drugs with different mechanisms of action, necessitates careful consideration of the potential drug-drug interactions (DDI) between the combined medicines. DDIs between inhibitors and substrates of metabolizing enzymes or transporters can cause serious adverse reactions. Therefore, prediction and evaluation of DDI potential is important in the clinic and in the drug development process.

It is increasingly recognized that drug transporters have a significant impact on DDIs by modulating the absorption, distribution, and excretion of drugs, alone or in interaction with drug-metabolizing enzymes $[16,25,26]$. In particular, screening of clinically important drug transporters such as OCT1, OCT2, OAT1, OAT3, OATP1B1, OATP1B3, P-gp, and BCRP in the drug development stage is recommended [16]. In this study, we investigated the inhibitory effects of DA-9801 on these transporters. IC 50 values of DA-9801 for these transporters were estimated to be 106, 174, >300, $48.1,273,>300,>300$, and $>300 \mu \mathrm{g} / \mathrm{mL}$, respectively (Figure 1).

It is important to note that in vivo human studies investigating the interactions between DA-9801 and substrates for the affected transporters such as OCT1, OCT2, and OAT3 are necessary to determine whether the in vitro inhibition of these transporters by DA-9801 is relevant or not. The inhibition of transport activities in vitro can be applied to herb-drug interaction potential in vivo with effective highest plasma concentration, plasma free fraction, and $\mathrm{IC}_{50}$ values of perpetrator [16]. However, DA-9801 is a herbal extract and, this has made elucidation of a single effective component and its plasma concentration difficult. Therefore, we aimed to investigate the in vivo herb-drug interaction potential in rats by using DA-9801 and either cimetidine, a simultaneous substrate for OCT1, OCT2, and OAT3, or furosemide, a substrate for OAT3.

The effective dose of DA-9801 for the therapeutics of diabetic neuropathy was $100-1,000 \mathrm{mg} / \mathrm{kg}$ in rats [6,7]. Therefore, we treated DA-9801 at a dose of 1,000 mg/kg in this study since the inhibitor has been treated at a maximum effective dose to investigate the highest possibility of in vivo herb-drug interaction. Then, although the experimental systems and species were not perfectly matched,

Table 2 Pharmacokinetic parameters of furosemide (10 $\mathrm{mg} / \mathrm{kg}$ ) after co-administration of DA-9801 at a single oral dose of $1,000 \mathrm{mg} / \mathrm{kg}$

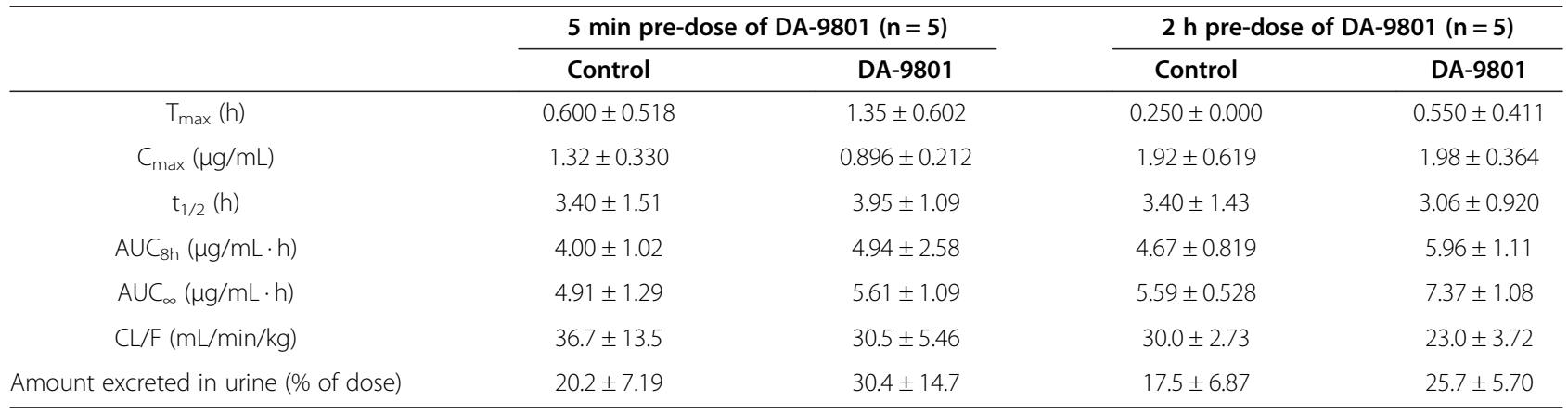




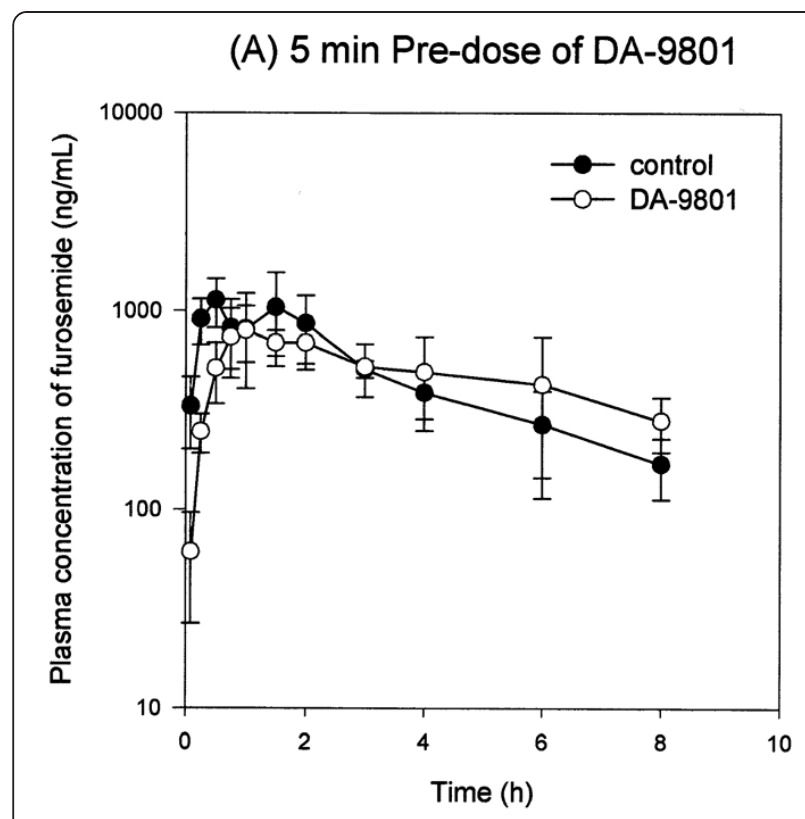

(B) $2 \mathrm{~h}$ Pre-dose of DA-9801

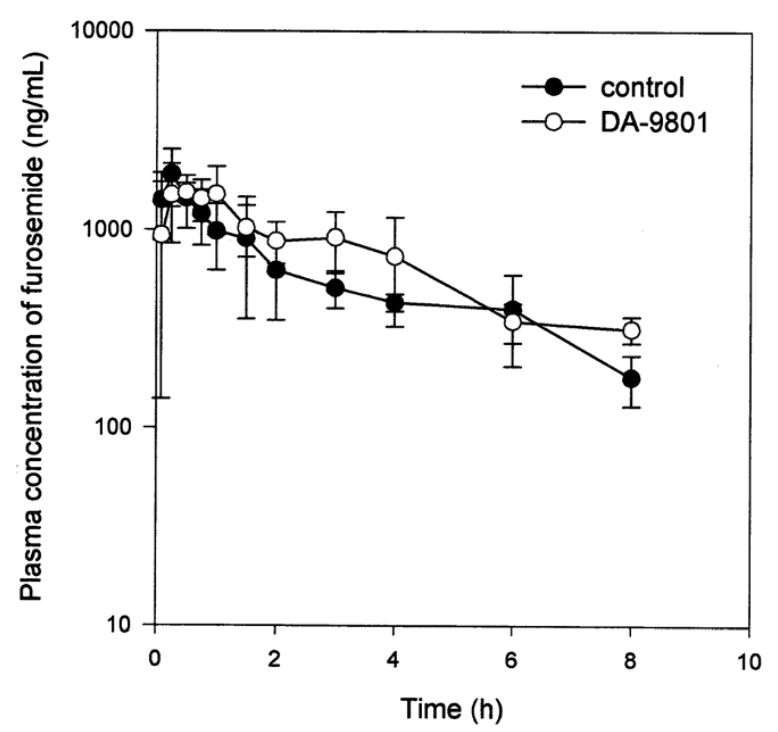

Figure 3 Plasma concentration-time curves of furosemide.

(A) Plasma concentration profile of furosemide in rats after oral administration of $10 \mathrm{mg} / \mathrm{kg}$ furosemide alone $(\bullet)$ and furosemide with 5 min pre-dose of 1,000 mg/kg DA-9801 (०). (B) Plasma concentration profile of furosemide in rats after oral administration of $10 \mathrm{mg} / \mathrm{kg}$ furosemide alone $(\bullet)$ and furosemide with $2 \mathrm{~h}$ pre-dose of 1,000 mg/kg DA-9801 (o). Each data point represents the mean \pm S.D. of five rats.

after determining the $\mathrm{IC}_{50}$ values of DA-9801 on the transport activity in HEK293 cells overexpressing human transporters such as OCT1, OCT2 and OAT3, we continued to evaluate in vivo herb-drug interactions between DA-9801 and substrates for Oct1, Oct2, and Oat3 in rats. Even though the tendency for the inhibitory potency of representative inhibitors in OCT and OAT transporters from different species such as mice, rat, rabbit, and humans, the $\mathrm{IC}_{50}$ values were different among them $[27,28]$. Therefore, we should note that a species difference in the transport activity between human and rat may account, in part, for the species difference in herb-drug interaction between DA-9801 and cimetidine and furosemide.

Cimetidine is a $\mathrm{H} 2$ receptor antagonist used for the treatment of peptic ulcers and related disorders. It is eliminated mainly by renal excretion in rats, with $70 \%$ eliminated by $72 \mathrm{~h}$ after oral ingestion without significant metabolism [29]. Cimetidine undergoes extensive tubular secretion in which Oct1/2 and Oat3 play major roles [23]. In case of 5 min pre-dose of DA-9801, $C_{\max }$ of cimetidine was lower and $\mathrm{T}_{\max }$ was greater than those in the control group. DA-9801 did not affect the $\mathrm{AUC}_{8 \mathrm{~h}}, \mathrm{AUC}_{\infty}, \mathrm{CL} / \mathrm{F}$, and $t_{1 / 2}$. With regard to $2 \mathrm{~h}$ pre-dose of DA-9801 prior to cimetidine, $\mathrm{C}_{\max }$ was slightly lower than that in the control group, but there was no difference in $\mathrm{T}_{\max }$ between treatment groups (Table 1 and Figure 2). Since average gastric emptying time in rats was about $30 \mathrm{~min}$ [30], differences in the $C_{\max }$ and $T_{\max }$ of cimetidine between 5 min pre-dose and $2 \mathrm{~h}$ pre-dose groups could be attributed to the presence and absence of DA-9801 in the stomach. After the removal of DA-9801 from the stomach (i.e. case of $2 \mathrm{~h}$ pre-dose of DA-9801), absorption phase of cimetidine tend to be similar to that in the control group. In addition, considering that Oat 3 and Oct $1 / 2$ were mainly involved in the renal excretion of cimetidine and that $\mathrm{CL} / \mathrm{F}$ and urinary excretion of cimetidine were not changed, DA-9801 (orally administered at a dose of $1,000 \mathrm{mg} / \mathrm{kg}$ ) affected the intestinal absorption of cimetidine but did not modulate the elimination pathway, which is mediated by Oat 3 and Oct $1 / 2$. This is supported by literature indicating that cimetidine was well absorbed after oral administration via paracellular pathway but its absorption was highly variable. Gastric $\mathrm{pH}$ and emptying variability have been reported to influence the absorption pattern of cimetidine as a function of dose and time of administration $[31,32]$.

Furosemide, an inhibitor of the $\mathrm{Na}^{+}-\mathrm{K}^{+}-2 \mathrm{Cl}^{-}$symport that is used as loop or high-ceiling diuretic, is eliminated mainly by renal excretion in rats, with $80-90 \%$ elimination by $72 \mathrm{~h}$ after intravenous injection without significant metabolism [24]. Furosemide undergoes extensive tubular secretion in which Oat1/3 play major roles [24]. Neither the $5 \mathrm{~min}$ pre-dose nor $2 \mathrm{~h}$ pre-dose of DA-9801 affected the pharmacokinetic parameters of furosemide (i.e., $\mathrm{AUC}_{8 \mathrm{~h}}, \mathrm{AUC}_{\infty}, \mathrm{CL} / \mathrm{F}, \mathrm{t}_{1 / 2}$, and amount excreted in urine). Taking all these results into consideration, DA-9801, a weak inhibitor of OAT3, did not cause in vivo herb-drug interactions that affected the pharmacokinetics of furosemide in rats. 


\section{Conclusions}

We have investigated the inhibitory effects of DA-9801 on transport activities of clinically important transporters and explored the in vivo herb-drug interaction potential between DA-9801 and target transporters such as OCT1, OCT2, and OAT3 at the maximum effective dose of DA-9801 in rats $(1,000 \mathrm{mg} / \mathrm{kg})$. While DA-9801 pre-dose (5 min or $2 \mathrm{~h}$ ) did not change the pharmacokinetics of furosemide, it decreased the $C_{\max }$ of cimetidine without changing AUC and $\mathrm{CL} / \mathrm{F}$. These results suggested that inhibitory effects of DA-9801 on OCT1, OCT2, and OAT3 transporters in vitro may not necessarily translate into in vivo herb-drug interaction in rats.

\section{Competing interests}

The authors have declared that no competing interests exist.

\section{Authors' contributions}

Conceived and designed the experiments: ISS, HEK, SZC, MS, HSL. Performed the experiments: ISS, TYK, HYJ, ENK, SSK. Analyzed the data: ISS, TYK, HUJ, ENK, SSK, HEK, SZC, MS, HSL. Wrote the paper: ISS, TYK, HUJ, ENK, SSK, HEK, SZC, MS, HSL. All authors read and approved the final manuscript.

\section{Acknowledgments}

This work was supported by the Global Leading Technology Program of the Office of Strategic R\&D Planning (OSP), funded by the Ministry of Knowledge Economy (MKE), Republic of Korea (10039303) and The Catholic University of Korea, 2011 (M-2011-B0002-00046).

\section{Author details}

${ }^{1}$ College of Pharmacy and Research Institute of Pharmaceutical Sciences, Kyungpook National University, Daegu 702-701, Korea. ${ }^{2}$ College of Pharmacy, The Catholic University of Korea, Bucheon 420-743, Korea. ${ }^{3}$ Research Center, Dong-A ST Co., Ltd., Yongin 446-905, Korea.

Received: 22 February 2014 Accepted: 14 July 2014

Published: 17 July 2014

\section{References}

1. Calcutt NA, Tomlinson DR, Willars GB, Keen P: Axonal transport of substance P-like immunoreactivity in ganglioside-treated diabetic rats. J Neurol Sci 1990, 96:283-291.

2. Vinik Al, Maser RE, Mitchell BD, Freeman R: Diabetic autonomic neuropathy. Diabetes Care 2003, 26:1553-1579.

3. Argoff CE, Cole BE, Fishbain DA, Irving GA: Diabetic peripheral neuropathic pain: clinical and quality-of-life issues. Mayo Clin Proc 2006, 81:S3-S11.

4. Choi SZ, Son MW: Novel botanical drug for the treatment of diabetic neuropathy. Arch Pharm Res 2011, 34:865-867.

5. Kim N, Kim SH, Kim YJ, Kim JK, Nam MK, Rhim H, Yoon SK, Choi SZ, Son M, Kim SY, Kuh HJ: Neurotrophic activity of DA-9801, a mixture extract of Dioscorea japonica Thunb. and Dioscorea nipponica Makino, in vitro. J Ethnopharmacol 2011, 137:312-319.

6. Jin HY, Kim SH, Yu HM, Baek HS, Park TS: Therapeutic Potential of Dioscorea Extract (DA-9801) in Comparison with Alpha Lipoic Acid on the Peripheral Nerves in Experimental Diabetes. J Diabetes Res 2013, 2013:631218.

7. Lee KA, Jin HY, Baek HS, Park TS: The Protective Effects of DA-9801 (Dioscorea Extract) on the Peripheral Nerves in Streptozotocin-Induced Diabetic Rats. J Nutr Sci Vitaminol (Tokyo) 2013, 59:437-446.

8. Ji HY, Liu KH, Kong TY, Jeong HU, Choi SZ, Son M, Cho YY, Lee HS: Evaluation of DA-9801, a new herbal drug for diabetic neuropathy, on metabolism-mediated interaction. Arch Pharm Res 2013, 36:1-5.

9. Choi YH, Chin YW, Kim YG: Herb-drug interactions: focus on metabolic enzymes and transporters. Arch Pharm Res 2011, 34:1843-1863.

10. Mohamed ME, Frye RF: Effects of herbal supplements on drug glucuronidation. Review of clinical, animal, and in vitro studies. Planta Med 2011, 77:311-321.
11. Borrelli F, Izzo AA: Herb-drug interactions with St John's wort (Hypericum perforatum): an update on clinical observations. AAPS $J$ 2009, 11:710-727.

12. Chen XW, Serag ES, Sneed KB, Liang J, Chew H, Pan SY, Zhou SF: Clinical herbal interactions with conventional drugs: from molecules to maladies. Curr Med Chem 2011, 18:4836-4850.

13. He SM, Chan E, Zhou SF: ADME properties of herbal medicines in humans: evidence, challenges and strategies. Curr Pharm Des 2011, 17:357-407

14. He SM, Yang AK, Li XT, Du YM, Zhou SF: Effects of herbal products on the metabolism and transport of anticancer agents. Expert Opin Drug Metab Toxicol 2010, 6:1195-1213.

15. Wu JW, Lin LC, Tsai TH: Drug-drug interactions of silymarin on the perspective of pharmacokinetics. J Ethnopharmacol 2009, 121:185-193.

16. Giacomini KM, Huang SM, Tweedie DJ, Benet LZ, Brouwer KL, Chu X, Dahlin A, Evers R, Fischer V, Hillgren KM, Hoffmaster KA, Ishikawa T, Keppler D, Kim RB, Lee CA, Niemi M, Polli JW, Sugiyama Y, Swaan PW, Ware JA, Wright SH, Yee SW, Zamek-Gliszczynski MJ, Zhang L: Membrane transporters in drug development. Nat Rev Drug Discov 2010, 9:215-236.

17. Choi MK, Song IS: Characterization of efflux transport of the PDE5 inhibitors, vardenafil and sildenafil. J Pharm Pharmacol 2012, 64:1074-1083

18. Choi YH, Lee U, Suh JH, Kim YG, Lee M, Oh E, Lee MG: Pharmacokinetic interaction between -acetamidocaproic acid (AACA) and cimetidine in indomethacin-induced acute gastric ulcer and control rats: inhibition of active renal secretion of AACA by cimetidine. Xenobiotica 2011, 41:409-415

19. Park JH, Lee WI, Yoon WH, Park YD, Lee JS, Lee MG: Pharmacokinetic and pharmacodynamic changes of furosemide after intravenous and oral administration to rats with alloxan-induced diabetes mellitus. Biopharm Drug Dispos 1998, 19:357-364.

20. Sun $X$, Tian $Y$, Zhang $Z$, Chen $Y$ : A single $L C$-tandem mass spectrometry method for the simultaneous determination of four $\mathrm{H} 2$ antagonists in human plasma. J Chromatogr B Analyt Technol Biomed Life Sci 2009, 877:3953-3959.

21. Sora DI, Udrescu S, Albu F, David V, Medvedovici A: Analytical issues in HPLC/MS/MS simultaneous assay of furosemide, spironolactone and canrenone in human plasma samples. J Pharm Biomed Anal 2010, 52:734-740.

22. Zhang S, Lovejoy KS, Shima JE, Lagpacan LL, Shu Y, Lapuk A, Chen Y, Komori T, Gray JW, Chen X, Lippard SJ, Giacomini KM: Organic cation transporters are determinants of oxaliplatin cytotoxicity. Cancer Res 2006, 66:8847-8857.

23. Zhang X, Groves CE, Bahn A, Barendt WM, Prado MD, Rodiger M, Chatsudthipong V, Burckhardt G, Wright SH: Relative contribution of OAT and OCT transporters to organic electrolyte transport in rabbit proximal tubule. Am J Physiol Renal Physiol 2004, 287:F999-F1010.

24. Brandoni A, Villar SR, Picena JC, Anzai N, Endou H, Torres AM: Expression of rat renal cortical OAT1 and OAT3 in response to acute biliary obstruction. Hepatology 2006, 43:1092-1100

25. Choi MK, Jin QR, Ahn SH, Bae MA, Song IS: Sitagliptin attenuates metformin-mediated AMPK phosphorylation through inhibition of organic cation transporters. Xenobiotica 2010, 40:817-825.

26. Chu X, Cai X, Cui D, Tang C, Ghosal A, Chan G, Green MD, Kuo Y, Liang Y, Maciolek CM, Palamanda J, Evers R, Prueksaritanont T: In vitro assessment of drug-drug interaction potential of boceprevir associated with drug metabolizing enzymes and transporters. Drug Metab Dispos 2013, 41:668-681.

27. Dresser MJ, Gray AT, Giacomini KM: Kinetic and selectivity differences between rodent, rabbit, and human organic cation transporters (OCT1). J Pharmacol Exp Ther 2000, 292:1146-1152.

28. Tahara H, Kusuhara H, Endou H, Koepsell H, Imaoka T, Fuse E, Sugiyama Y: A species difference in the transport activities of $\mathrm{H} 2$ receptor antagonists by rat and human renal organic anion and cation transporters. J Pharmacol Exp Ther 2005, 315:337-345

29. Kurata T, Muraki Y, Mizutani H, Iwamoto T, Okuda M: Elevated systemic elimination of cimetidine in rats with acute biliary obstruction: the role of renal organic cation transporter OCT2. Drug Metab Pharmacokinet 2010, 25:328-334

30. Franklin RA: The influence of gastric emptying on plasma concentrations of the analgesic, meptazinol. Br J Pharmacol 1977, 59:565-569. 
31. Oberle RL, Amidon GL: The influence of variable gastric emptying and intestinal transit rates on the plasma level curve of cimetidine; an explanation for the double peak phenomenon. J Pharmacokinet Biopharm 1987, 15:529-544.

32. Piyapolrungroj N, Zhou YS, Li C, Liu G, Zimmermann E, Fleisher D:

Cimetidine absorption and elimination in rat small intestine. Drug Metab Dispos 2000, 28:65-72.

doi:10.1186/1472-6882-14-251

Cite this article as: Song et al.: Evaluation of the transporter-mediated herb-drug interaction potential of DA-9801, a standardized dioscorea extract for diabetic neuropathy, in human in vitro and rat in vivo. BMC Complementary and Alternative Medicine 2014 14:251.

\section{Submit your next manuscript to BioMed Central and take full advantage of:}

- Convenient online submission

- Thorough peer review

- No space constraints or color figure charges

- Immediate publication on acceptance

- Inclusion in PubMed, CAS, Scopus and Google Scholar

- Research which is freely available for redistribution 